\title{
A Case Study on Implementation of $5 S$ in a Manufacturing Plant to Improve Operational Effectiveness
}

\author{
Ofentse Monnanyana ${ }^{1}$ and Kapil Gupta ${ }^{1, *}$ \\ ${ }^{1}$ Mechanical and Industrial Engineering Technology, University of Johannesburg, 2028 \\ Johannesburg, South Africa
}

\begin{abstract}
S}$ is one of the important industrial engineering techniques to obtain workplace organization and efficiency enhancement. This paper reports a case study on implementation of $5 \mathrm{~S}$ in a factory facility of a valve manufacturing company. The aim behind implementing $5 \mathrm{~S}$ is to improve the productivity and efficiency by reducing the factory chaos, reducing the tool and material search time, and arranging the workplace for a better visibility of the machines, equipment, and items. Audit checklists, workplace pictures, and time study have been used to analyse the effect of $5 \mathrm{~S}$ implementation. A strategic 5S implementation in this work resulted in much better workplace organization; improved visibility, appearance, and orderliness of objects; and significant reduction in the time to search or access tools.
\end{abstract}

\section{Introduction}

Workplace organization is one of the prime areas of concern in industrial engineering and management. Several strategies and techniques have been worked out to achieve sustainability in industries by a better and proper workplace organization. The Japanese technique $5 \mathrm{~S}$ is one of such techniques that is used more or less used in every industry and company [1]. 5S is a group of five Ss used for a better workplace organization. This technique is often misunderstood as a cleaning technique for shop floors and workshops. Rather it is a set of techniques to maintain orderliness and cleanliness, reduce wastages, and enhance efficiency and productivity $[2,3]$.

Japanese products have become known for being amongst the top ranked products in the world. In the mid-1950's, companies that were manufacturing in Japan were forced by the shortage of resources to come up with a methodology in which all the scrap that was produced to be reused so at to have no wastage. $5 \mathrm{~S}$ was initially introduced in the early 1980's by Takashi Osada, it was thought that implementation of the $5 \mathrm{~s}$ practice would raise the performance for the production lines significantly and also safety, health, housekeeping and much more [3, 4]. In recent years, the $5 \mathrm{~S}$ practice has commonly being used in many of the companies across the globe with the purpose of enhancing productivity and capability [4-7].

\footnotetext{
*Corresponding author: kgupta@uj.ac.za
} 
The concept of 5S is originated from the five Japanese words- Seiri (Sort), Seiton (Set in order), Seiso (Shine), Seiketsu (Standardize) and Shitsuke (Sustain) [1, 2].

Vaidya et al. [4] conducted a study on implementation of 5S in a workshop and scored the implementation effectiveness. A proper survey of the workplace which includes measuring the whole place according to their different zones was done. The areas of interests are presented with pictures before and after implementation. The improvement of the implementation lead to, better usage of the working area, minimized waste, reduced search time for documents and equipment, and eliminate duplication of unwanted materials.

A case study on implementation of $5 \mathrm{~S}$ in a polish manufacturing company obtained a clean and arranged workplace with a very less budget [5]. Extensive employee cooperation and contribution have been reported towards making new rules and maintaining standards.

Khumalo and Gupta $[6,7]$ reported a case study on implementation and effectiveness of $5 \mathrm{~S}$ in a university workplace. They conducted a comprehensive investigation and successfully minimized the workplace abnormalities, minimized the tool search time, and improved the workplace appearance for a better visibility of the objects. They successfully trained staff and claimed to initiate the culture for sustenance of $5 \mathrm{~S}$ with high employee morale. Their approach was recognized to be a big contribution towards establishing a sustainable university.

The present work considers the case of a company manufactures of valves and distributes pumps for the mineral processing, power generation, water and effluent markets. The current state of absence of $5 \mathrm{~s}$ within the business has led to there being lack of order or chaos in the factory, tool-boxes are without the sufficient tools, workstations are untidy, not cleaned at regular intervals or at shift changes. This has led to an efficient workplace which ultimately has a ripple effect on outputs. In other words, the area of concern within the factory is that of tooling and components that are disorganized, improper demarcation of work areas which contributes to a workplace that is not conducive for working and this has resulted in low customer product output and business profit.

Considering this problem, 5S technique was adopted to overcome the aforementioned problems and improve productivity and efficiency. The next sections will provide the details on the methodology adopted for implementing $5 \mathrm{~S}$ and discuss the findings.

\section{Methodology}

The first and the main aspect of methodology to implement 5S was the training to inform all the relevant stakeholders within the business about the need and objective of implementing $5 \mathrm{~s}$. Thereafter, a $5 \mathrm{~S}$ committee was formed, followed by setting up the $5 \mathrm{~S}$ Zones which includes red tagging of holding area, mini business areas, elect champions, and facilitators. The specialized 5S training was conducted for the managers involved which was followed by the procurement of the key $5 \mathrm{~S}$ materials/tools/boards. Investigation and understanding the issues of concern which exist within the factory, exact requirements as regards to the implementation of all 5Ss, and possible restructuring or reorganizing the factory space and workplace with the assistance of factory employee were done.

Figures 1-4 shows the state of the factory prior to $5 \mathrm{~s}$ implementation. The condition as shown in the pictures necessitated implementation of $5 \mathrm{~S}$.

Implementation of all 5Ss has been done by following the appropriate strategies and all actions were agreed to be recorded in the "Action Plan Form/Register" and displayed in the Mini Business Area.

The first ' $\mathrm{S}$ ' which is for Sort, is focused on the elimination of all of the unnecessary items from the factory. This phase removes all the unnecessary clutter by using red tags as a means of visual control, evaluate all the items within the factory to determine if their presence adds value. This will keep the factory clear of materials that are not needed. The idea is to 
identify the red-tag targets, attach the tag, document the results of red-tagging (use the red tag-form/register), move the identified red-tagged items to the local demarcated holding red tagging area and then perform an evaluation of the items in the $5 \mathrm{~S}$ hold area, ensuring the best decision regarding final disposition of tagged items. This will in turn increase the amount of useful space within the factory and as part of safety remove all the hazardous obstacles that could lead to danger.

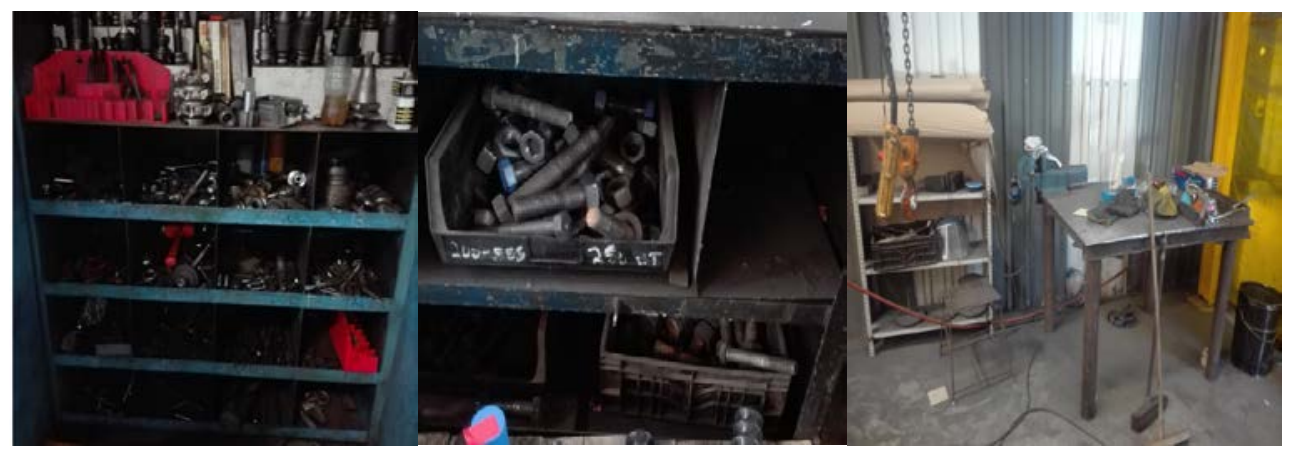

Fig. 1. Factory floor (Machine shop) state needs Sorting of the items.

The second ' $\mathrm{S}$ ' which for Set in Order, is focused on creation of workplace that is informative visually and is orderly. This second phase of $5 \mathrm{~s}$ implementation changes in the workplace by marking all the necessary locations by means of creation of addresses or locations by allocating labels, markings and the use colour coding within the factory.

This phase emphasizes the importance of organizing items needed in a way that best supports the employees doing the work. This is done by making signs and labels to properly identify and sign-post the areas to eliminate confusion. The factory workplace condition which needs set in order is shown in Fig 2.

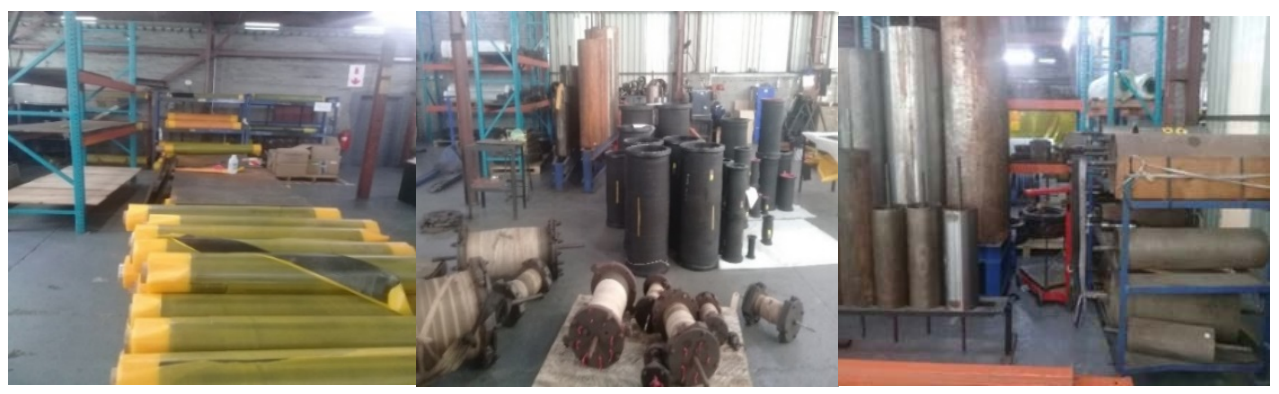

Fig. 2. Factory workplace condition which needs to set the items in order.

The third ' $\mathrm{S}$ ' which is Shine, is focused on removal of dirt and other debris (Fig. 3), this means that all equipment and the workplace would need to be inspected in order to remove all the sources that lead to contamination. The targeted outcome is a clean workplace that shines and minimizes sources of contamination. This has been achieved by determining what is to be cleaned and the methods to be used.

The fourth ' $S$ ' which is standardize, is focused on establishing all the necessary standards to maintain all the $5 \mathrm{~S}$ improvements. The targeted outcomes are to develop procedures, all the necessary checklists and other mechanics to maintain a working environment that is visually informative. This is achieved by agreeing on the standards on the set standards and agreeing on the 5 s rules. Fig 4 shows how necessary it is to standardize in the factory. 


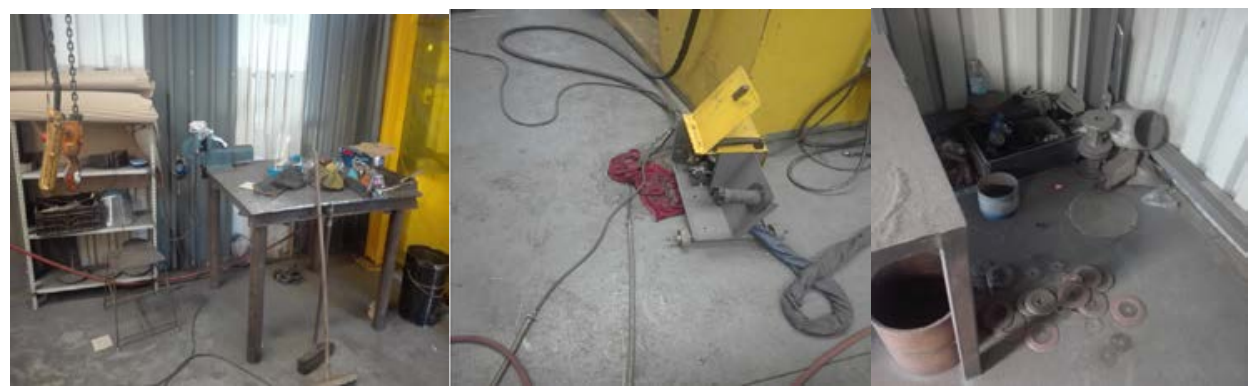

Fig. 3. Factory floor (Machine shop) state needs Sorting of the items.

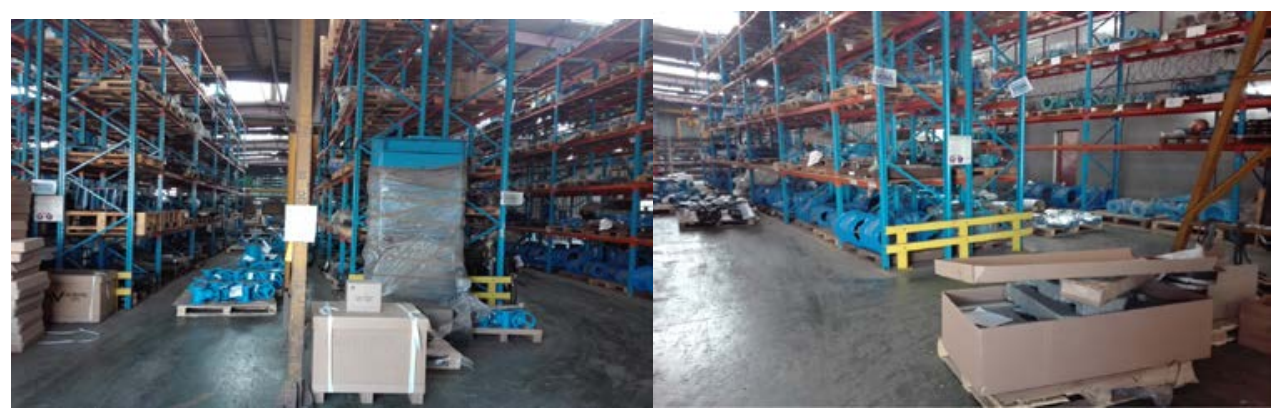

Fig. 4. Factory workplace reveals the need of standardization to enhance the arrangement of items.

The fifth ' $\mathrm{S}$ ' which is to sustain, is focused on monitoring, expanding and refining all the results gained in the implementation process. The targeted outcomes are that of a workplace or factory that is able to restore order automatically, is able to regulate itself and be able to continuously improve itself.

Having recorded and audited the factory prior to $5 \mathrm{~s}$ implementation, it was critically important to have a reference point that could visually highlight to both employees and management where the factory was in terms of pre implementing of $5 \mathrm{~s}$ and to continually document progress made by the factory by using audits and pictures.

From the pre $5 \mathrm{~s}$ implementation checklist audits, the following scores are evident:

Sort- 5\%, Set in order- 10\%, Shine- 15\%, Standardize- 5\%, Sustain- 5\%.

The pre-implementation audit conducted and the images provided above clearly show that the factory was in a total state of chaos and needed urgent interventions to stop losses, wastages, and for better workplace utilization and organization that eventually affect overall productivity and efficiency.

\section{Findings and Discussion}

Before the start of the implementation of $5 \mathrm{~s}$, the factories and other departments such as component stores were not in a good state, the tool drawers were not organized and this led to time being wasted searching for the appropriate tools to use for jobs. The time study method was then used on specific persons within the machine floor to investigate how much time was consumed in order to move around and search for tools, in worst case scenarios, operators had to borrow tools from other operators. 
Table 1 below shows the times taken to search for tools, the idea behind this study is to show how time wasted on searching for tools impacts productivity within the factory. The times were recorded prior $5 \mathrm{~S}$ implementation.

Table 1. Results of time study conducted before implementing 5S.

\begin{tabular}{|c|c|c|c|c|c|c|c|c|c|c|}
\hline $\begin{array}{r}\text { SI } \\
\text { No }\end{array}$ & Tool & 1 & 2 & 3 & 4 & 5 & $\begin{array}{l}\text { Total } \\
\text { Time }\end{array}$ & $\begin{array}{l}\text { Mean } \\
\text { Averag } \\
\text { e Time } \\
\text { in Min } \\
\end{array}$ & $\begin{array}{c}\text { Standar } \\
\mathrm{d} \\
\text { Deviati } \\
\text { on }\end{array}$ & $\begin{array}{c}\text { Varia } \\
\text { nce }\end{array}$ \\
\hline 1 & Clamp & 12,32 & 10,58 & 13,40 & 12,40 & 11,60 & 60,30 & 12,06 & \begin{tabular}{|l|}
0,88 \\
\end{tabular} & 0,94 \\
\hline 2 & Drill Bit & 4,50 & 7,50 & 4,20 & 5,50 & 5,70 & 27,40 & 5,48 & 1,35 & 1,16 \\
\hline 3 & $\begin{array}{l}\text { Tap (Metric/ } \\
\text { Imperial)- } \\
\text { (Travelling to } \\
\text { stores) }\end{array}$ & 18,90 & 20,50 & 16,50 & 22,50 & 19,80 & 98,20 & 19,64 & 3,87 & 1,97 \\
\hline 4 & $\begin{array}{l}\text { Vernier } \\
\text { Caliper }\end{array}$ & 4,53 & 5,01 & 8,32 & 7,43 & 5,32 & 30,61 & 6,12 & 2,19 & 1,48 \\
\hline 5 & 5 Ton Crane & 10,53 & 13,45 & 17,23 & 24,50 & 4,23 & 69,94 & 13,99 & 45,70 & 6,76 \\
\hline 6 & Spanners & 7,23 & 3,32 & 4,23 & 3,38 & 3,23 & 21,39 & 4,28 & 2,31 & 1,52 \\
\hline 7 & $\begin{array}{c}\text { Inserts } \\
\text { (travelling to } \\
\text { stores) }\end{array}$ & 23,31 & 29,32 & 23,38 & 27,32 & 28,92 & 132,25 & 26,45 & 6,88 & 2,62 \\
\hline 8 & $\mathrm{U}$ drill & 6,62 & 3,45 & 4,12 & 4,18 & 4,92 & 23,29 & 4,66 & 1,18 & 1,09 \\
\hline 9 & Hydro Drill & 3,32 & 4,21 & 3,38 & 3,12 & 3,35 & 17,38 & 3,48 & 0,14 & 0,38 \\
\hline 10 & $\begin{array}{l}\text { Torque } \\
\text { Wrench }\end{array}$ & 4,28 & 4,58 & 4,69 & 4,55 & 4,76 & 22,86 & 4,57 & 0,03 & 0,16 \\
\hline 11 & Sockets & 2,32 & 2,89 & 2,77 & 2,11 & 2,95 & 13,04 & 2,608 & 0,11 & 0,33 \\
\hline
\end{tabular}

With that being said, $5 \mathrm{~s}$ is not about just keeping the workplace clean, the time sheet clearly shows that the time spent on searching for tools does have a ripple effect on the output or productivity of the business. It is also important to show that the implementation of $5 \mathrm{~s}$ is definitely the basis of any improvement initiative moving forward. An analysis was done after compiling a list of tooling and hand machines that are required in the factory, after that a budget was allocated to procure all the necessary tools so as to make work much easier in each workstation. The same 5 samples as per pre $5 \mathrm{~s}$ implementation was done for this experiment post the $5 \mathrm{~s}$ implementation.

With the implemented changes, from the results it can been seen that there is an improvement in the times (table 2). Shorter times looking for tooling means that productivity and efficiency at each workstation is increased. 
Table 2. Results of time study conducted after $5 \mathrm{~S}$ implementation.

\begin{tabular}{|c|c|c|c|c|c|c|c|c|c|c|}
\hline SI No & Tool & 1 & 2 & 3 & 4 & 5 & $\begin{array}{c}\text { Total } \\
\text { Time }\end{array}$ & $\begin{array}{c}\text { Mean } \\
\text { Average } \\
\text { Time in } \\
\text { Min }\end{array}$ & $\begin{array}{c}\text { Standard } \\
\text { Deviation }\end{array}$ & Variance \\
\hline 1 & Clamp & 5,20 & 6,00 & 5,62 & 5,82 & 5,53 & 28,17 & 5,63 & 0,27 & 0,07 \\
\hline 2 & Drill Bit & 2,22 & 2,32 & 2,00 & 2,33 & 2,12 & 10,99 & 2,20 & 0,12 & 0,02 \\
\hline 3 & $\begin{array}{c}\text { Tap(Metric/Imperial)- } \\
\text { (placed by the machine }\end{array}$ & 1,17 & 1,93 & 1,96 & 2,03 & 1,91 & 9,00 & 1,80 & 0,32 & 0,10 \\
\hline 4 & Vernier Caliper & 1,11 & 1,12 & 1,23 & 1,01 & 1,02 & 5,49 & 1,10 & 0,08 & 0,01 \\
\hline 5 & 5 Ton Crane & 1,02 & 1,03 & 1,00 & 24,50 & 4,23 & 31,78 & 6,36 & 9,16 & 83,85 \\
\hline 6 & Spanners & 0,96 & 0,82 & 1,00 & 0,76 & 88,00 & 91,54 & 18,31 & 34,85 & 12,1425 \\
\hline 7 & $\begin{array}{c}\text { Inserts (placed by the } \\
\text { machine) }\end{array}$ & 0,82 & 0,77 & 0,69 & 1,00 & 1,23 & 4,51 & 0,90 & 0,19 & 0,04 \\
\hline 8 & U drill & 1,02 & 1,23 & 1,11 & 1,13 & 1,12 & 5,61 & 1,12 & 0,07 & 0,00 \\
\hline 9 & Hydro Drill & 1,00 & 1,02 & 1,23 & 1,22 & 1,29 & 5,76 & 1,15 & 0,12 & 0,01 \\
\hline 10 & Torque Wrench & 4,28 & 4,58 & 4,69 & 4,55 & 4,76 & 22,86 & 4,57 & 0,16 & 0,03 \\
\hline 11 & Sockets & 1,02 & 1,11 & 1,10 & 1,09 & 1,12 & 5,44 & 1,088 & 0,04 & 0,00 \\
\hline
\end{tabular}

Figure 5 presents post-implementation pictures of the factory. The effectiveness of $5 \mathrm{~S}$ implementation is evident from the pictures where it is seen that the factory workplace and facilities are sorted, arranged in order, clean and shiny, and can be identified easily.

Post 5S implementation audit checklists scores are as follows:

Sort- 90\%, Set in Order- 75\%, Shine- 70\%, Standardize- 90\%, Sustain- 95\%.

A significant and substantive improvement has been obtained when compared with the pre-implementation states. Although that these results are not at a $100 \%$, it must be understood that $5 \mathrm{~S}$ is a basis for continuous improvement and its not a once-off project. The efforts of all employees and stakeholders are commendable irrespective of the minor issues in the implementation.
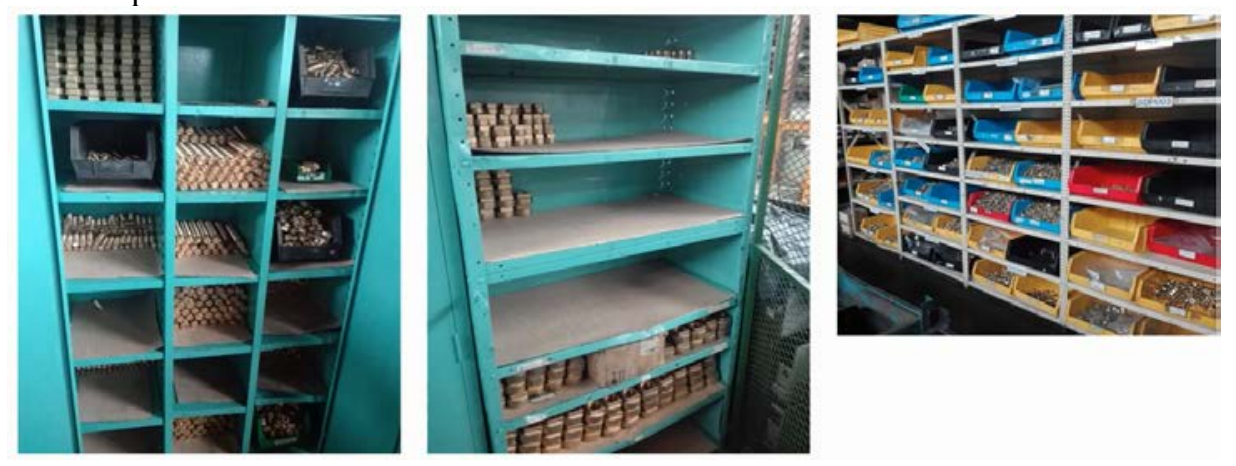


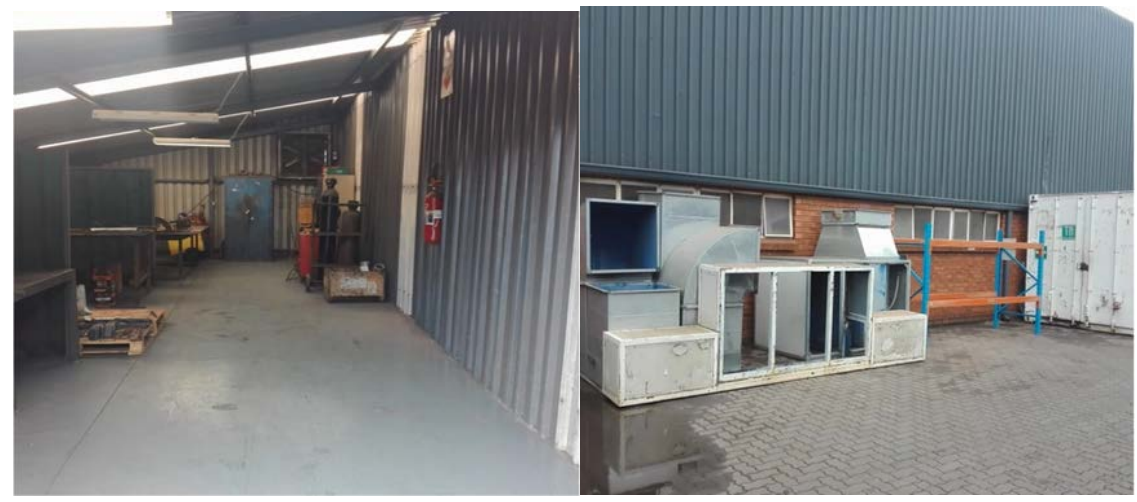

Fig. 5. Factory workplace after $5 \mathrm{~S}$ implementation.

\section{Conclusion}

This paper reported a case study on implementation of $5 \mathrm{~S}$ in a facility of a valve manufacturing company. The implementation effectiveness has been measured in terms of scores on audit checklists for all $5 \mathrm{~S}$, time study conducted to access certain items in the factory space, and pictures. The post-implementation results confirm that the implementation of $5 \mathrm{~S}$ has been effective and resulted in a significant improvement in factory workplace organization; reduction in time taken to identify, access and search tools and other items; and better visibility of the tool, equipment, and material. This will lead to the overall improvement in productivity and efficiency of the company.

We acknowledge Dynamic fluid control Pty Ltd, South Africa for necessary support to execute this case study.

\section{References}

1. R. Gapp, R. Fisher, K. Kobayashi, Management Decision 46, 4 (2008)

2. O. Omogbai, K. Salonitis, The implementation of $5 \mathrm{~S}$ lean tool using system dynamics approach. In Proceedings of the 27th CIRP Design, (2017)

3. C. Costa, L. Ferreira, C. Jose, F. Silva, Implementation of 5S Methodology in a Metalworking Company, Chapter 01 in DAAAM International Scientific Book, B. Katalinic (Ed.) (2018)

4. R.D. Vaidya, R. Trivedi, T. Rathi, S. Niwal, S. Panbude, International Journal of Advance Research and Innovative Ideas in Education, 3, 2 (2017)

5. N. Upadhye, S.G. Deshmukh, S. Garg, International Journal of Management Science and Engineering Management, 5, 5 (2010)

6. V. Khumalo, K. Gupta, A Case Study on Effectiveness of 4S Implementation in a Machine Shop. In Proceedings of the International Conference on Industrial Engineering and Operations Management, Pilsen, Czech Republic, July 23-26, (2019)

7. V. Khumalo, K. Gupta, Implementation of Shitsuke for Sustaining with 5S Culture in a Mechanical Workshop. In Proceedings of the International Conference on Industrial Engineering and Operations Management, Pilsen, Czech Republic, July 23-26, (2019) 